\title{
Genetic association between 1425G/A SNP in PRKCH and hypertrophic cardiomyopathy in a Chinese population
}

\author{
Feng $\mathrm{Ji}^{1, *}$, Qun Liu ${ }^{2, *}$, Zeyu Feng ${ }^{3}$, Xinwei Han ${ }^{1}$ and Zhitong Li ${ }^{1}$ \\ ${ }^{1}$ Department of Interventional Radiology, The First Affiliated Hospital of Zhengzhou University, Zhengzhou 450052, China \\ ${ }^{2}$ Johns Hopkins University School of Medicine, Baltimore, MD 21224, USA \\ ${ }^{3}$ Medical School of Nantong University, Nantong 226001, China \\ *These authors have contributed equally to this work \\ Correspondence to: Feng Ji, email: jifeng061 1 @hotmail.com \\ Keywords: hypertrophic cardiomyopathy; genetics; polymorphism; hypertrophic obstructive cardiomyopathy; PRKCH \\ Abbreviations: HCM: hypertrophic cardiomyopathy; SCD: sudden cardiac death; PKC: protein kinase C; HOCM: hypertrophic \\ obstructive cardiomyopathy; LVOTO: left-ventricular outflow tract obstruction \\ Received: August 13, $2017 \quad$ Accepted: September 23, $2017 \quad$ Published: October 31, 2017 \\ Copyright: Ji et al. This is an open-access article distributed under the terms of the Creative Commons Attribution License 3.0 \\ (CC BY 3.0), which permits unrestricted use, distribution, and reproduction in any medium, provided the original author and source \\ are credited.
}

\section{ABSTRACT}

\begin{abstract}
Hypertrophic cardiomyopathy is a heterogeneous myocardial disorder with a broad spectrum of clinical presentation and morphologic features. Previous reports indicated that protein kinase $\mathrm{C}$ pathway as a major determinant of cardiac hypertrophy and heart failure. Population-based analyses of the association between PRKCH gene (encoded PKCn) and HCM has not been performed yet. The purpose of this study is to investigate the association of the nonsynonymous SNP (1425G/A) in PRKCH gene and hypertrophic cardiomyopathy in a Chinese population. 323 patients with HCM and 326 controls were examined using a case-control methodology. The 1425G/A SNP in PRKCH was genotyped by allele-specific real-time PCR assay. The 1425G/A SNP in PRKCH increased the risk of HOCM (hypertrophic obstructive cardiomyopathy) $(\mathrm{OR}=1.427,95 \%$ confidence interval, 1.013 to $2.012, P=0.046)$ under a dominant model. After age- and sex-adjustment, the significant associations remained in HOCM (for GG +AG versus AA, OR= 2.497, 95\% confidence interval, 1.01 to 6.17; $P=0.047$ ). The 1425G/A SNP in PRKCH increases the risk of hypertrophic obstructive cardiomyopathy in the Chinese population.
\end{abstract}

\section{INTRODUCTION}

Hypertrophic cardiomyopathy (HCM) is the most commonly primary autosomal dominant inherited myocardial disease characterized by unexplained myocardial hypertrophy leading to progressive ventricular dysfunction and sudden cardiac death (SCD) [1]. As a global disease, HCM may affect groups of all age ethnicity, with an estimated prevalence more than 1 in 500 people worldwide [2]. Recognition of HCM is important, both for providing treatment and prevention strategies and in triggering the initiation of clinical and genetic surveillance of family members [3].
To date, over 1,400 responsible mutations have been documented in more than 25 genes [4], the most important genes encode the protein components of the cardiac sarcomere, which perform contractile, structural and regulatory functions. These include thick filament proteins ( $M Y H 7$, MYL2, and MYL3), thin filament proteins (TNNT2, TNNI3, TNNC1, TPM1, and ACTC), intermediate filament proteins (MYBPC3), and Z-disc proteins (ACTN2, MYOZ2). Mutations in the myosin heavy chain (MYH7) and myosin-binding protein $\mathrm{C}(M Y B P C 3)$ are the most common and account for roughly $80 \%$ of sarcomeric HCM [5]. With increased understanding of the molecular genetic causes of HCM and advances in modern laboratory 
technology, clinical genetic testing for HCM has become increasingly feasible [1]. However, HCM is clinically heterogeneous, with inter- and intra- familial variations ranging from benign forms to malignant forms with a high risk of cardiac failure or SCD [5], biochemical and biophysical analyses have shown that there is no unifying abnormality of cardiac contractility resulting from mutations of identified causal genes [6, 7]. Patients carrying the same mutation have a considerably different clinical spectrum and prognosis in the inter- and intrafamily [8-10]. This suggest that the phenotype of HCM is not simply a direct consequence of altered contractility and a more fundamental abnormality of myocardial function, new variants and environmental factors should be explored.

In genome wide association studies, the PRKCH gene, which encodes $\mathrm{PKC \eta}$, has been reported as a novel susceptibility gene for atherosclerotic diseases such as cerebral infarction [11] and was involved in the development and progression of atherosclerosis in humans [12]. Observations in cell culture and animal models implicated protein kinase $\mathrm{C}$ (PKC) as an important signal transduction pathway in the development of cardiac hypertrophy [13]. PKC is a serine-threonine kinase that regulates a wide variety of important cellular functions including proliferation, differentiation and apoptosis [13]. A 1425G/A SNP (single nucleotide polymorphism) (leading to V374I) of PRKCH gene which lies in exon 9 and within the ATP-binding site of PKC $\eta$ enhances the kinase activity [14]. Therefore, we focused on the association of the nonsynonymous SNP (1425G/A) in $\mathrm{PRKCH}$ gene and HCM in an independent case-control sample.

\section{RESULTS}

Between February 2011 and October 2013, 323 HCM cases and 326 controls were enrolled. Of the cases, $60.7 \%$ were male, with mean age of $55.9 \pm 16.7$ years. The characteristics of the study participants are shown in Table 1. The ratio of age, sex, weight, height and blood pressure, we calculated the BMI (body mass index) of individuals at the first interview (baseline) and prevalence of diabetes in cases were not different from those in controls. DBP (diastolic blood pressure) were lower in cases than those of in controls.

The percentage of patients with hypertrophic obstructive cardiomyopathy (HOCM) and non-obstructive cardiomyopathy is $70.6 \%$ (228) and $29.4 \%$ (95) of overall patients respectively. We genotyped the $1425 \mathrm{G} / \mathrm{A}$ SNP in PRKCH (rs2230500) in the cohort (Table 2). The SNP was in Hardy-Weinberg equilibrium $(\mathrm{P}>0.05)$. Associations between the 1425G/A SNP in PRKCH and different types of HCM are shown in Table 2. The allele of A increased the risk of $\operatorname{HOCM}(\mathrm{OR}=1.43, \mathrm{P}=0.046)$ whereas no significant association can be found between this allele and nonobstructive cardiomyopathy $(\mathrm{OR}=1.108, \mathrm{P}=0.781)$.
For further clarify the independent effect of the 1425G/A SNP in PRKCH, we performed multivariate analysis with adjustment for demographic factors using a conditional logistic regression model in 228 individuals with HOCM along with age- and sex-matched controls. Odds ratios for the incidence of HOCM were shown in Table 3. The 1425G/A SNP in PRKCH increased the risk of HOCM (age- and sex-adjusted odds ratio= $3.41 ; 95 \%$ $\mathrm{CI}, 1.05$ to $11.05 ; \mathrm{P}=0.041)$ under a dominant model. For $1425 \mathrm{G} \rightarrow \mathrm{A}$, age- and sex-adjusted odds ratio of AA genotype was $2.49(95 \% \mathrm{CI}, 1.01$ to $6.17 ; \mathrm{P}=0.047)$ under a recessive model.

\section{DISCUSSION}

In the present study, we examined the $1425 \mathrm{G} / \mathrm{A}$ SNP in PRKCH with HCM in the Chinese population. This SNP was previously shown to increase the risk of ischemic stroke and cerebral hemorrhage in Chinese [11] and Japanese population [15], and a higher risk genotype for severe gastric atrophy [16]. Recent research implicates $\mathrm{PKC}$ activation in the pathophysiology of a number of cardiovascular disease states [13, 17]. Our results showed the first time that the $1425 \mathrm{G} / \mathrm{A}$ SNP in PRKCH increases the risk of HOCM (Table 2 and Table 3 ) and this association remains significant under dominant and recessive models after age- and sex-adjustment.

The gene PRKCH encodes protein kinase $\mathrm{C}$, which is a family of serine- and threonine-specific protein kinases that can be activated by calcium and the second messenger diacylglycerol. PKC family members phosphorylate a wide variety of protein targets and are known to be involved in diverse cellular signaling pathways and regulates multiple important cellular functions, including proliferation, differentiation, and apoptosis [13]. Research data from conventional animal models, genetically engineered mice and human myocardium implicate activation of the PKC pathway as a major determinant of cardiac hypertrophy and heart failure [18]. Even though there are species-specific differences present in the differential PKC isoform response, the action of PKC in general is a common pathway in the development of cardiac hypertrophy [18].

$\mathrm{PRKCH}$ is located in chromosome 14q22-q23 in human and the $1425 \mathrm{G} / \mathrm{A}$ SNP (leading to Val374Ile) is located within an ATP-binding site (exon 9) of PKCn enhances the kinase activity [19]. Previous studies showed that the nonsynonymous SNP in PRKCH increases the risk of stroke in the Japanese and Chinese population [15, 19] and confer increased risk of RA through aberrant $T$ cell-mediated autoimmune responses [20], and act as a higher risk genotype for severe gastric atrophy due to the dysregulation of $\mathrm{PKC \eta}$ signal transduction pathway(s) [16]. Contrary to other PKCs, which are primarily enriched in the brain tissue, $\mathrm{PKC} \eta$ is mainly expressed in lung, skin and heart tissues [21]. PKC $\eta$ participates 
Table 1: Basic Characteristics of Study Participants

\begin{tabular}{lccc}
\hline & HCM Patients $(\mathbf{n}=\mathbf{3 2 3})$ & Controls $(\mathbf{n}=\mathbf{3 2 6})$ & P Value \\
\hline Age $($ years $)$ & $55.87 \pm 16.65$ & $56.22 \pm 14.71$ & 0.758 \\
Male $(\%)$ & 60.70 & 63.20 & 0.282 \\
BMI $\left(\mathrm{kg} / \mathrm{m}^{2}\right)$ & $24.93 \pm 3.15$ & $25.04 \pm 3.17$ & 0.699 \\
SBP $(\mathrm{mmHg})$ & $123.82 \pm 20.46$ & $124.20 \pm 13.58$ & 0.806 \\
DBP $(\mathrm{mmHg})$ & $74.93 \pm 12.12$ & $79.89 \pm 9.75$ & 0.000 \\
DM $(\%)$ & 5.9 & 7.4 & 0.275 \\
\hline
\end{tabular}

*BMI = weight $(\mathrm{Kg}) /$ height $(\mathrm{m})^{2}$; SBP: systolic blood pressure; DBP: diastolic blood pressure.

Table 2: Case-Control Study Showing Association between the 1425G/a SNP in PRKCH and HCM

\begin{tabular}{|c|c|c|c|c|c|c|c|c|c|c|c|c|c|c|}
\hline \multirow{2}{*}{ Samples } & \multicolumn{5}{|c|}{ Case } & \multicolumn{5}{|c|}{ Control } & \multicolumn{2}{|c|}{ MAF } & \multicolumn{2}{|c|}{ Unadjusted $(\mathrm{A} / \mathrm{G})$} \\
\hline & $\mathbf{A A}$ & AG & GG & Sum & H-W & $\mathbf{A A}$ & AG & GG & Sum & H-W & Case & Control & Odds Ratio 95\% CI & P Value \\
\hline \multicolumn{15}{|l|}{ Screening } \\
\hline $\mathrm{HCM}$ & 16 & 95 & 206 & 317 & 0.250 & 7 & 86 & 233 & 326 & 0.775 & 0.200 & 0.153 & $1.383(1.036,1.845)$ & 0.028 \\
\hline Obstructive & 11 & 69 & 144 & 224 & 0.468 & 4 & 62 & 165 & 231 & 0.505 & 0.203 & 0.152 & $1.427(1.013,2.012)$ & 0.046 \\
\hline Non-obstructive & 5 & 22 & 66 & 93 & 0.102 & 3 & 24 & 68 & 95 & 0.626 & 0.172 & 0.158 & $1.108(0.691,1.718)$ & 0.781 \\
\hline
\end{tabular}

Table 3: Odds Ratios for the Incidence of Hypertrophic Obstructive Cardiomyopathy

\begin{tabular}{ccccc}
\hline \multirow{2}{*}{$\begin{array}{c}\text { Genotype of the } \\
\text { 1425G/A SNP }\end{array}$} & No. of Case & Total No. of Subjects & \multicolumn{2}{c}{ Age- and Sex-Adjusted } \\
\cline { 3 - 4 } GG & 144 & 309 & Odds Ratio (95\% CI) & P Value \\
\hline AG & 69 & 11 & 131 & $1.32(0.87,2.00)$ \\
AA & 213 & 15 & $3.41(1.05,11.05)$ & 0.196 \\
GG+AG & 11 & 440 & 1.00 \\
AA & & 15 & $2.50(1.01,6.17)$ \\
\hline
\end{tabular}

in various cellular processes including proliferation, differentiation, secretion and apoptosis [22-24]. Recent reports have revealed the role of $\mathrm{PKC \eta}$ in immune function [25]. PKC $\eta$ was shown to be important for T-cell proliferation and homeostasis [26], and was also implicated in the regulation of toll-like receptor-2 (TLR-2) responses in macrophages [27]. Centurione et al reported $\mathrm{PKC} \eta$ regulated the hypertrophic and apoptotic events in rat neonatal heart through regulating NF-kB signaling system and intrinsic mitochondrial apoptotic route of rat life [28].

Noteworthy, results from our study showed the $1425 \mathrm{G} / \mathrm{A}$ SNP in PRKCH increased the risk of HOCM under a dominant model whereas no statistical significance can be observed between 1425G/A SNP in $\mathrm{PRKCH}$ and non-HOCM. These findings are in agreement with the well-recognized knowledge that left-ventricular outflow tract obstruction (LVOTO) is a hallmark of a worse prognosis [29]. Furthermore, our study indicate the 1425G/A SNP in PRKCH as a biomarker for definition of differences in presenting features and long-term mortality between non-HCM and HOCM.

However, some limitations should be kept in mind in this work. First, the number of subjects is relatively small in non-HOCM treatment group, and it may have insufficient statistical power to determine the relationship between PRKCH 1425G/A and non-HOCM. In addition, the mechanism and the signaling pathway of PRKCH are very complex. Thus, more molecular and cellular experiments should be performed to further illuminate the mechanism involved. 
In conclusion, our study showed that the $1425 \mathrm{G} / \mathrm{A}$ SNP in PRKCH were significantly associated with HOCM in a Chinese population suggesting the PRKCH gene encoding $\mathrm{PKC} \eta$ as a putative candidate gene conferring genetic susceptibility to HOCM in a Chinese population. Although PRKCH certainly has biologic plausibility as an HOCM gene, replication studies in other independent populations and/or by family-based tests of association are essential to confirm the observations. Further investigations into the molecular mechanisms by which PRKCH alters HOCM susceptibility are also required.

\section{MATERIALS AND METHODS}

\section{Subjects recruitment}

The HCM patients of this study were recruited from the First Affiliated Hospital of Zhengzhou University during 2010 to 2013. All patients had hypertrophic cardiomyopathy as diagnosed by echocardiograms showing unexplained left ventricular hypertrophy. Inclusion criteria included $\geq 13 \mathrm{~mm}$ thickness of the left ventricular wall and $\geq 1: 3$ of the ratio of interventricular septum thickness to posterior wall thickness of the left ventricle with unknown causes of LVH shown by echocardiography [1]. Left ventricular outflow obstruction was defined as a peak instantaneous gradient at least $30 \mathrm{mmHg}$ under basal (resting) conditions attributable to systolic anterior motion (SAM) of the mitral valve. Exclusion criteria included secondary cardiac hypertrophy related to other cardiovascular diseases, such as hypertension, valvar heart disease, pulmonary hypertension, coronary heart disease and metabolic diseases that may cause LVH revealed by medical history and physical examination, echocardiography or coronary angiography. Of the 323 patients, 262 had sporadic HCM and 61 had family history of HCM.

Control subjects were selected according to the case control study criteria in the same geographic location (control subjects matched to cases by sex, age and blood pressure), who had no history or symptoms of cardiovascular diseases shown by medical history, physical examination and echocardiography.

The study was approved by Institutional Review Borad of the First Affiliated Hospital of Zhengzhou University and informed consent were obtained from all study participants upon enrolment.

\section{Genotyping}

Totally, 649 participants $(323 \mathrm{HCM}$ cases and 326 controls) were recruited and blood samples were collected after a 12-hour overnight fast and stored at $-70^{\circ} \mathrm{C}$ until use. Biochemical variables including serum sodium, potassium, creatinine, uric acid, blood urea nitrogen (BUN), total plasma cholesterol, triglyceride, high density lipoprotein cholesterol (HDL-C), low density lipoprotein cholesterol (LDL-C), and blood glucose were analyzed according to standard protocols.

Genomic DNA was extracted from cellular buffy coat using QIAamp DNA Blood Midi Kit. The 1425G/A SNP in PRKCH (rs2230500) was genotyped by allelespecific real-time polymerase chain reaction using GeneAmp 5700 Sequence Detector (Applied Biosystem).

\section{The PCR amplifications were performed using the following primers}

Common primer, 5'-GCAGAATCACGTCCTTC TTCAG-3'-;

Allele-specific primer (A), 5'-CATAGGTGATGC TTGCAAGAA-3';

Allele-specific primer (G), 5'-CATAGGTGATGC TTGCAAGAG-3';

Individual DNA sample was genotyped for single SNP by using an equal aliquot of samples with 2 allelespecific PCR reactions, each containing 1 of the allelespecific (A-S) primers and a common primer. PCR reaction with the $A-S$ primer that matched the allele in the template DNA amplified normally, whereas PCR reaction with the other A-S primer that mismatched the allele in the template was prevented or delayed when PCR reaction was monitored in real-time (by including SYBR Green I in the PCR and following fluorescence cycle-by-cycle). For each amplification, a fluorescence threshold near the baseline fluorescence was used to calculate a cycle threshold value, which was then used to call the genotype of the sample. PCR was carried out on the GeneAmp 5700 Sequence Detector with procedure of 12 minutes at $95^{\circ} \mathrm{C}$, followed by 45 cycles of 30 seconds at $95^{\circ} \mathrm{C}, 30$ seconds at $58^{\circ} \mathrm{C}$, and finished by 20 minutes dissociation at $60^{\circ} \mathrm{C}$. Genotype was directly obtained with the GeneAmp 5700 SDS software. The genotyping call rate was $98 \%$ and the concordance between our genotyping and direct sequencing was $100 \%$ by direct sequencing 100 random samples.

\section{Statistical analysis}

Clinical data about continuous variables expressed as mean $\pm \mathrm{SD}$, and differences between groups were assessed by Student's t-test. Categorical variables were represented as percentage and were tested by $\mathrm{X}^{2}$ analysis. Hardy-Weinberg equilibrium was also assessed by $\mathrm{X}^{2}$ analysis. Our analyses concerned the whole study group and were subsequently stratified by 2 major types of HCM, HOCM and non-HOCM. In each stratum, cases were compared with the corresponding control groups. Odds ratios in dominant model with corresponding $95 \%$ confidence intervals were computed by the Woolf's method to test the effect of genotype on HCM risk. Adjusted odds ratios for age and sex were performed by 
multiple logistic regression with genotypes, age and sex as the independent variables. Data were analyzed using SAS statistical software (version 9.1, SAS Institute Inc). $\mathrm{P}<0.05$ was used to indicate statistically significant differences.

\section{Author contributions}

Study design and monitor: Feng ji.

Data collection: Xinwei Han, Zhitong Li.

Analysis and interpretation of data: Qun Liu and Zeyu Feng.

Drafting of the manuscript: Liu Qun.

\section{CONFLICTS OF INTEREST}

The authors declare that they have no conflicts of interest.

\section{FUNDING}

This work was supported in part by The Capital Health Research and Development of Special Grant (China) to QL. (2011-7041-01).

\section{REFERENCES}

1. Elliott PM, Anastasakis A, Borger MA, Borggrefe M, Cecchi F, Charron P, Hagege AA, Lafont A, Limongelli G, Mahrholdt H, McKenna WJ, Mogensen J, Nihoyannopoulos P, et al. 2014 ESC guidelines on diagnosis and management of hypertrophic cardiomyopathy: the task force for the diagnosis and management of hypertrophic cardiomyopathy of the European Society of Cardiology (ESC). Eur Heart J. 2014; 35: 2733-79. https://doi.org/10.1093/eurheartj/ ehu284.

2. Semsarian C, Ingles J, Maron MS, Maron BJ. New perspectives on the prevalence of hypertrophic cardiomyopathy. J Am Coll Cardiol. 2015; 65: 1249-54. https://doi.org/10.1016/j.jacc.2015.01.019.

3. Maron BJ. Hypertrophic cardiomyopathy: an important global disease. Am J Med. 2004; 116: 63-5. https://doi. org/10.1016/j.amjmed.2003.10.012.

4. Dadson K, Kauck L, Billia F. Molecular mechanisms in cardiomyopathy. Clin Sci. 2017; 131: 1375-92. https://doi. org/10.1042/CS20160170.

5. Keren A, Syrris P, McKenna WJ. Hypertrophic cardiomyopathy: the genetic determinants of clinical disease expression. Nat Clin Pract Cardiovasc Med. 2008; 5: 158-68. https://doi.org/10.1038/ncpcardio1349.

6. Wu B, Wang L, Liu Q, Luo Q. Myocardial contractile and metabolic properties of familial hypertrophic cardiomyopathy caused by cardiac troponin I gene mutations: a simulation study. Exp Physiol. 2012; 97: 15569. https://doi.org/10.1113/expphysiol.2011.059956.
7. Muthu P, Liang J, Schmidt W, Moore JR, Szczesna-Cordary D. In vitro rescue study of a malignant familial hypertrophic cardiomyopathy phenotype by pseudo-phosphorylation of myosin regulatory light chain. Arch Biochem Biophys. 2014; 552-3: 29-39. https://doi.org/10.1016/j. abb.2013.12.011.

8. Bratt EL, Sparud-Lundin C, Ostman-Smith I, Axelsson AB. The experience of being diagnosed with hypertrophic cardiomyopathy through family screening in childhood and adolescence. Cardiol Young. 2012; 22: 528-35. https://doi. org/10.1017/S1047951111002101.

9. Jáchymová M, Muravská A, Paleček T, Kuchynka P, Řeháková H, Magage S, Král A, Zima T, Horký K, Linhart A. Genetic variation screening of TNNT2 gene in a cohort of patients with hypertrophic and dilated cardiomyopathy. Physiol Res. 2012; 61: 169-75.

10. Charitakis K, Basson CT. Can genetic testing improve our aim in hypertrophic cardiomyopathy? Circ Res. 2010; 106: 1446-8. https://doi.org/10.1161/ CIRCRESAHA.110.220343.

11. Zhang Z, Xu G, Zhu W, Cao L, Yan B, Liu X. PRKCH $1425 \mathrm{G} / \mathrm{A}$ polymorphism predicts recurrence of ischemic stroke in a Chinese population. Mol Neurobiol. 2015; 52: 1648-53. https://doi.org/10.1007/s12035-014-8964-6.

12. Torisu K, Zhang X, Nonaka M, Kaji T, Tsuchimoto D, Kajitani K, Sakumi K, Torisu T, Chida K, Sueishi K, Kubo M, Hata J, Kitazono T, et al. PKC $\eta$ deficiency improves lipid metabolism and atherosclerosis in apolipoprotein E-deficient mice. Genes Cells. 2016; 21: 1030-48. https:// doi.org/10.1111/gtc. 12402 .

13. Singh RM, Cummings E, Pantos C, Singh J. Protein kinase $\mathrm{C}$ and cardiac dysfunction: a review. Heart Fail Rev. 2017. https://doi.org/10.1007/s10741-017-9634-3.

14. Uchida Y, Sugiura S, Nakashima T, Ando F, Shimokata H. Contribution of $1425 \mathrm{G} / \mathrm{A}$ polymorphism in protein kinase C-Eta $(\mathrm{PRKCH})$ gene and brain white matter lesions to the risk of sudden sensorineural hearing loss in a Japanese nested case-control study. J Neurogenet. 2011; 25: 82-7. https://doi.org/10.3109/01677063.2011.591462.

15. Li J, Luo M, Xu X, Sheng W. Association between 1425G/A SNP in PRKCH and ischemic stroke among Chinese and Japanese populations: a meta-analysis including 3686 cases and 4589 controls. Neurosci Lett. 2012; 506: 55-8. https:// doi.org/10.1016/j.neulet.2011.10.047.

16. Goto Y, Hishida A, Matsuo K, Tajima K, Morita E, Naito M, Wakai K, Hamajima N. PRKCH gene polymorphism is associated with the risk of severe gastric atrophy. Gastric Cancer. 2010; 13: 90-4. https://doi.org/10.1007/ s10120-009-0542-7.

17. Zeng C, Liang B, Jiang R, Shi Y, Du Y. Protein kinase C isozyme expression in right ventricular hypertrophy induced by pulmonary hypertension in chronically hypoxic rats. Mol Med Rep. 2017;16: 3833-40. https://doi.org/10.3892/ mmr.2017.7098. 
18. Jalili T, Takeishi Y, Walsh RA. Signal transduction during cardiac hypertrophy: the role of G alpha q, PLC beta I, and PKC. Cardiovasc Res. 1999; 44: 5-9. https://doi. org/10.1016/S0008-6363(99)00211-4.

19. Kubo M, Hata J, Ninomiya T, Matsuda K, Yonemoto K, Nakano T, Matsushita T, Yamazaki K, Ohnishi Y, Saito S, Kitazono T, Ibayashi S, Sueishi K, et al. A nonsynonymous $\mathrm{SNP}$ in PRKCH (protein kinase $\mathrm{C}$ eta) increases the risk of cerebral infarction. Nat Genet. 2007; 39: 212-7. https://doi. org/10.1038/ng1945.

20. Takata Y, Hamada D, Miyatake K, Nakano S, Shinomiya F, Scafe CR, Reeve VM, Osabe D, Moritani M, Kunika K, Kamatani N, Inoue H, Yasui N, et al. Genetic association between the PRKCH gene encoding protein kinase Ceta isozyme and rheumatoid arthritis in the Japanese population. Arthritis Rheum. 2007; 56: 30-42. https://doi. org/10.1002/art.22262.

21. Bacher N, Zisman Y, Berent E, Livneh E. Isolation and characterization of PKC-L, a new member of the protein kinase C-related gene family specifically expressed in lung, skin, and heart. Mol Cell Biol. 1991; 11: 126-33.

22. Raveh-Amit H, Hai N, Rotem-Dai N, Shahaf G, Gopas $\mathrm{J}$, Livneh E. Protein kinase $\mathrm{C} \eta$ activates NF-kappaB in response to camptothecin-induced DNA damage. Biochem Biophys Res Commun. 2011; 412: 313-7. https://doi. org/10.1016/j.bbrc.2011.07.090.

23. Fima E, Shtutman M, Libros P, Missel A, Shahaf G, Kahana G, Livneh E. PKCeta enhances cell cycle progression, the expression of G1 cyclins and p21 in MCF-7 cells. Oncogene. 2001; 20: 6794-804. https://doi.org/10.1038/ sj.onc. 1204885 .
24. Akkaraju GR, Basu A. Overexpression of protein kinase C-eta attenuates caspase activation and tumor necrosis factor-alpha-induced cell death. Biochem Biophys Res Commun. 2000; 279: 103-7. https://doi.org/10.1006/ bbrc.2000.3903.

25. Quann EJ, Liu X, Altan-Bonnet G, Huse M. A cascade of protein kinase $\mathrm{C}$ isozymes promotes cytoskeletal polarization in T cells. Nat Immunol. 2011; 12: 647-54. https://doi.org/10.1038/ni.2033.

26. Fu G, Hu J, Niederberger-Magnenat N, Rybakin V, Casas J, Yachi PP, Feldstein S, Ma B, Hoerter JA, Ampudia J, Rigaud S, Lambolez F, Gavin AL, et al. Protein kinase $\mathrm{C} \eta$ is required for $\mathrm{T}$ cell activation and homeostatic proliferation. Sci Signal. 2011; 4: ra84. https://doi. org/10.1126/scisignal.2002058.

27. Park DW, Lee HK, Lyu JH, Chin H, Kang SW, Kim YJ, Bae YS, Baek SH. TLR2 stimulates ABCA1 expression via PKC- $\eta$ and PLD2 pathway. Biochem Biophys Res Commun. 2013; 430: 933-7. https://doi.org/10.1016/j. bbrc.2012.11.135.

28. Simonis G, Briem SK, Schoen SP, Bock M, Marquetant $\mathrm{R}$, Strasser RH. Protein kinase $\mathrm{C}$ in the human heart: differential regulation of the isoforms in aortic stenosis or dilated cardiomyopathy. Mol Cell Biochem. 2007; 305: 103-11. https://doi.org/10.1007/s11010-007-9533-3.

29. Pelliccia F, Pasceri V, Limongelli G, Autore C, Basso C, Corrado D, Imazio M, Rapezzi C, Sinagra G, Mercuro G. Long-term outcome of nonobstructive versus obstructive hypertrophic cardiomyopathy: a systematic review and meta-analysis. Int J Cardiol. 2017; 243:379-84. https://doi. org/10.1016/j.ijcard.2017.06.071. 